\title{
ARRANJOS DE PRODUTIVIDADES DE HÍBRIDOS DE MILHO ATRAVÉS DE ADUBAÇÕES FOSFATADAS E NITROGENADAS
}

\author{
Francisco Carlos Almeida de Souza ${ }^{1}$; José Arledo Marques de Souza ${ }^{1}$; Paulo César \\ Ramos Oliveira ${ }^{1}$; Ricardo Augusto Martins Cordeiro². \\ ${ }^{1}$ Estudante de Agronomia do Instituto Federal de Educação, Ciência e Tecnologia do Pará, Núcleo de Pesquisa e \\ Difusão Tecnológica Agropecuária, Campus Castanhal. Castanhal, Pará, Brasil. agrocarlosifpa@ hotmail.com \\ ${ }^{2}$ Professor, Doutor do Instituto Federal de Educação, Ciência e Tecnologia do Pará, Núcleo de Pesquisa e \\ Difusão Tecnológica Agropecuária, Campus Castanhal. Castanhal, Pará, Brasil.
}

\begin{abstract}
RESUMO: O milho (Zea mays L.) é um dos mais importantes cereais do mundo, pois representa a base da alimentação humana e animal. Este trabalho objetivou avaliar o desempenho de produtividade de grãos de milho em dois sistemas de cultivo (consorciado com capim e solteiro) de acordo com as adubações utilizadas: fosfatadas e nitrogenadas. Para isto o estudo foi desenvolvido no IFPA Campus Castanhal, sob Latossolo Amarelo distrófico em sistema de sequeiro. Foram avaliadas adubações fosfatadas e nitrogenadas, dois híbridos de milho, o 30F80 e o 30P70 em dois sistemas de cultivo, solteiro e consorciado com Brachiaria brizantha cv. Marandú em delineamento experimental de blocos ao acaso, com quatro repetições. Os resultados obtidos de produtividade de grãos de milho demonstraram que houve diferença entre os tratamentos avaliados. Os resultados de produtividade de grãos apresentaram-se superiores quando foram utilizadas adubações fosfatadas, pois com adubações nitrogenadas de cobertura foram alcançados $4316,75 \mathrm{~kg} \mathrm{ha}^{-1}$, no entanto com aplicação de adubação fosfatada no momento do plantio, $300 \mathrm{~kg}$ de $\mathrm{P}_{2} \mathrm{O}_{5} \mathrm{ha}^{-1}$. A utilização de adubação fosfatada proporcionou os melhores resultados de produtividade de grãos de milho nas condições avaliadas.
\end{abstract}

PALAVRAS-CHAVE: Integração lavoura-pecuária, fertilidade do solo, Zea mays L.

\section{ARRANGEMENTS PRODUCTIVITIES HYBRID CORN THROUGH AND NITROGEN PHOSPHATE FERTILIZATIONS}

\begin{abstract}
Corn (Zea mays L.) is one of the most important cereals in the world; it represents the base of the food and feed. This work aimed to evaluate the productivity of corn in two cropping systems (intercropping with grass and single) according to the fertilizers used: nitrogen and phosphorus. For this study was developed in the IFPA Campus Castanhal under Yellow dystrophic Oxisol in dryland system. Were evaluated phosphate and nitrogen fertilizers, two corn hybrids, and the 30F80 30P70 in two cropping systems, single and intercropped with Brachiaria brizantha cv. Marandú experiment in a randomized block design with four replications. The results of grain yield of maize showed that there were differences among the treatments in this study. The results of grain yield showed up higher when phosphate fertilizers were used, as with nitrogen fertilization coverage were reached $4316.75 \mathrm{~kg} \mathrm{ha}^{-1}$, however with the application of phosphate fertilizer at planting, $300 \mathrm{~kg} \mathrm{P}_{2} \mathrm{O}_{5}$ $\mathrm{ha}^{-1}$. The use of phosphate fertilizer resulted in the best grain yield of maize in the conditions of this study.
\end{abstract}

KEY-WORDS: Crop-livestock integration, soil fertility, Zea mays L. 


\section{INTRODUÇÃO}

O milho (Zea mays L.) é um cereal que hoje em dia apresenta grande importância para o agronegócio mundial, por apresentar grande importância, tanto na alimentação humana como animal. Além disso, atualmente, sua produção vem aumentando, para ser utilizado como matéria-prima na fabricação de etanol, que vem ganhando os mercados mundiais.

Para alcançar altas produtividades são necessários técnicas de manejo que aliadas ao potencial genético das variedades utilizadas estejam em consonância. Nessa perspectiva os sistemas de Integração Lavoura-Pecuária (ILP), objetivam o consórcio da cultura do milho com capim para forragem e, sem dúvida, a que desperta maior interesse, devido ao fato de que, com ele, é possível produzir grãos ou silagem de milho que, depois de colhidos, deixam uma pastagem que, em pouco tempo, aproximadamente 40 dias, estará disponível para uso (ALVARENGA et al., 2008).

As adubações utilizadas para a produção de grãos de milho são altamente importantes, pois influenciam diretamente no rendimento. As fontes de nitrogênio e fósforo bem como a quantidade a serem aplicadas nas lavouras são de fundamental importância.

Este trabalho objetivou avaliar o desempenho de produtividade de grãos de milho em dois sistemas de cultivo (consorciado com capim e solteiro) de acordo com as adubações utilizadas: fosfatadas e nitrogenadas.

\section{MATERIAL E MÉTODOS}

Este trabalho foi realizado sob condições de sequeiro no Instituto Federal de Educação, Ciência e Tecnologia do Pará, Campus Castanhal, localizado em Castanhal, PA, Brasil (latitude $1^{\circ} 17^{\prime}$ 26", Sul e longitude $47^{\circ} 55^{\prime} 28^{\prime}$ ' Oeste). O clima é to tipo Equatorial Ami, classificação de Koppen, com temperatura média de $25^{\circ} \mathrm{C}$ e máxima de $40^{\circ} \mathrm{C}$ (SANTOS et al., 2006).

O tipo de solos onde foi realizado o experimento classifica-se como Latossolo Amarelo distrófico textura média, com as seguintes características químicas na profundidade 0-20cm: $\mathrm{pH}$ em água 5,1; N\% 0,14; MO 11,34 $\mathrm{g} \mathrm{kg}^{-1}$; P $4 \mathrm{mg} \mathrm{dm}^{-3}$; $\mathrm{K} 21 \mathrm{mg} \mathrm{dm}^{-3}$; $\mathrm{Na} 15 \mathrm{mg} \mathrm{dm}^{-3}$; $\mathrm{Ca}+\mathrm{Mg} \mathrm{1,2}$ $\mathrm{cmol}_{\mathrm{c}} \mathrm{dm}^{-3} ; \mathrm{H}+\mathrm{Al} \mathrm{5,2} \mathrm{cmol}_{\mathrm{c}} \mathrm{dm}^{-3}$.

Foram avaliadas adubações fosfatadas e nitrogenadas em dois híbridos de milho, o 30F80 e o 30P70 sob dois sistemas de cultivo, solteiro e consorciado com Brachiaria brizantha cv. Marandú. O preparo de área foi o mesmo para ambas as áreas, com duas gradagens profundas e uma de nivelamento. Para avaliar a adubação fosfatada foram realizadas dois tratamentos, T1: $300 \mathrm{~kg} \mathrm{ha}^{-1}$ de $\mathrm{P}_{2} \mathrm{O}_{5}$ e 100 de NPK 30:00:20 na adubação de 
cobertura e $\mathrm{T} 2: \quad 0 \quad \mathrm{~kg}^{-1}$ ha ${ }^{-1} \quad \mathrm{P}_{2} \mathrm{O}_{5}$ utilizando a mesma quantidade de adubo em cobertura e $100 \mathrm{~kg} \mathrm{ha}^{-1}$ de NPK 20:00:20 no momento do plantio.

Para avaliar as adubações nitrogenadas de acordo com o sistema de cultivo foram realizadas três adubações, sendo uma de plantio e duas de cobertura em ambas as áreas. $\mathrm{Na}$ adubação de plantio foi utilizado $300 \mathrm{~kg} \mathrm{ha}^{-1}$ de NPK 08:28:16 e na primeira adubação de cobertura $100 \mathrm{~kg} \mathrm{ha}^{-1}$ de NPK 20:00:20 aos 26 dias após o plantio, no período em que as plantas desenvolviam a quarta folha expandida, e a segunda adubação $100 \mathrm{~kg} \mathrm{ha}^{-1}$ de NPK 20:00:20 aos 32 dias, quando as plantas desenvolviam a sexta folha expandida.

Para ambos os anos agrícolas utilizou-se o delineamento experimental de blocos ao acaso, com quatro repetições, sendo no ano agrícola 2010/11 dois tratamentos avaliados, T1: $300 \mathrm{~kg} \mathrm{ha}^{-1}$ de $\mathrm{P}_{2} \mathrm{O}_{5}, \mathrm{~T} 2: 0 \mathrm{~kg} \mathrm{ha}^{-1}$ de $\mathrm{P}_{2} \mathrm{O}_{5}$, e no ano agrícola 2011/12 também dois tratamentos avaliados, milho solteiro (30P70) e consorciado com capim (30F80).

Cada parcela experimental era constituída de $10 \mathrm{~m}^{2}$, totalizando 62 plantas por parcela, com espaçamento de $0,8 \times 0,2 \mathrm{~m}$, com uma de densidade de 62.500 plantas $\mathrm{ha}^{-1}$. Os resultados de produtividade de grãos foram submetidos à análise estatística através do teste de Tukey a $5 \%$ de probabilidade (SILVA; AZEVEDO, 2009).

\section{RESULTADOS E DISCUSSÃO}

\section{Adubações fosfatadas com o híbrido 30F80 solteiro}

Os resultados obtidos de produtividade de grãos de milho demonstraram que houve diferença entre os tratamentos avaliados, tanto no que diz respeito à aplicação de adubação fosfata no início do plantio quanto aos sistemas de cultivos adotados (Tabela 1).

Os resultados alcançados nesta pesquisa no que se refere a produtividade de grãos estão de acordo com Collier et al. (2008), e ainda o nível de fósforo no solo em estudo elevou-se de $1 \mathrm{mg} \mathrm{dm}^{-3}$ de $\mathrm{P}$ para $9 \mathrm{mg} \mathrm{dm}^{-3}$ de $\mathrm{P}$, representando um aumento de $900 \%$ na concentração de fósforo no solo.

Tabela 1. Valores médios de produtividade de grãos (PG) de milho, em kg ha ${ }^{-1}$, em função dos tratamentos avaliados.

\begin{tabular}{lc}
\hline Tratamentos & Produtividade de kg de grãos ha $^{-1}$ \\
\hline $\mathrm{T} 1\left(300 \mathrm{~kg} \mathrm{P}_{2} \mathrm{O}_{5}\right)$ & $5.280 \mathrm{a}$ \\
$\mathrm{T} 2\left(0 \mathrm{~kg} \mathrm{P}_{2} \mathrm{O}_{5}\right)$ & $4.440 \mathrm{~b}$ \\
\hline
\end{tabular}

Médias seguidas pela mesma letra não diferiram entre si pelo teste de Tukey, ao nível de 5\% de probabilidade. 
A produtividade por hectare em $\mathrm{T} 2$ aponta um acréscimo de $4.480 \mathrm{~kg} / \mathrm{ha}$ ou $264 \%$ em relação à média obtida pelo município de Castanhal no ano 2008 (SAGRI, 2010), isto representa acréscimo de $3280 \mathrm{~kg} \mathrm{ha}^{-1}$ a mais do que o rendimento no município de Castanhal-PA.

\section{Adubações nitrogenadas com o híbrido $30 \mathrm{F80}$ solteiro e 30P70 consorciado com Brachiaria brizantha cv. Marandú}

Na Tabela 2 são apresentados os resultados de produtividades de milho utilizando adubações nitrogenadas, em sistema de cultivo-SC solteiro (MHS) e consorciado (MBL) com Brachiaria brizantha cv. Marandú, os híbridos 30P70 e 30F80 respectivamente. Em relação a produtividade de grãos de milho o SC solteiro se mostrou estatisticamente superior quando comparado ao SC consorciado com forrageira.

Tabela 2. Produtividade de milho nos sistemas de cultivo aos 120 DAE.

\begin{tabular}{lc}
${ }^{1}$ Sistema de cultivo & Produtividade de kg de grãos ha $^{-1}$ \\
\hline MHS 30P70 & $4316,75 \mathrm{a}$ \\
MBL 30F80 & $4093,75 \mathrm{~b}$ \\
\hline
\end{tabular}

${ }^{\text {IS }}$ Sistemas de cultivo, onde MHS = milho híbrido solteiro; MBL = Milho híbrido consorciado com Brachiaria. As médias seguidas pela mesma letra na coluna não diferem estatisticamente entre si pelo Teste de Tukey $(\mathrm{P}<0,05)$.

Os resultados de produtividade de grãos apresentaram-se superiores quando foram utilizadas adubações fosfatadas, pois com adubações nitrogenadas de cobertura foram alcançados $4316,75 \mathrm{~kg} \mathrm{ha}{ }^{-1}$, no entanto com aplicação de adubação fosfatada no momento do plantio, $300 \mathrm{~kg}$ de $\mathrm{P}_{2} \mathrm{O}_{5} \mathrm{ha}^{-1}$ obteve-se produtividades equivalentes a $5280 \mathrm{~kg} \mathrm{ha}^{-1}$, demonstrando a eficácia da adubação fosfatada. Pois de acordo com Malavolta et al. (2002) age diretamente na produção de energia para a planta, auxiliando nos processos de absorção de minerais e na síntese de proteínas. Com o $\mathrm{P}$ em quantidades adequadas as plantas desenvolvem bem o sistema radicular para facilitar a absorção de nutrientes.

$\mathrm{Na}$ Tabela 2 foi demonstrada a produtividade de grãos de dois híbridos, utilizando as mesmas adubações, porém em sistemas de cultivo diferentes, onde o sistema de cultivo solteiro se sobressaiu daquele consorciado.

Alvarenga et al. (2011), ao avaliarem o cultivo de milho solteiro e consorciado com Brachiaria brizantha cv. Marandú descrevem que a produtividade não variou com o tratamento, pois resultados não foram significativamente diferentes $(\mathrm{p}<$ 
0,05), sugerindo que a produtividade do milho pode ser mantida em sistemas consorciados com capim, quando atendida as condições de fertilidade do solo e controle de pragas e doenças que restringem as produtividades das gramíneas.

Vale ressaltar que essas diferentes produtividades podem estar associadas ao potencial genético dos híbridos utilizados nos sistemas de cultivo. Cobucci (2001) afirmou que é possível manter a produtividade do milho e ter um pasto formado na sequência em Integração Lavoura-Pecuária-ILP.

\section{CONCLUSÃO}

A utilização de adubação fosfatada proporcionou os melhores resultados de produtividade de grãos de milho nas condições deste estudo.

Houve provável interferência da forrageira na produtividade de milho com dois híbridos diferentes, sendo que o 30F80 apresentou o menor rendimento. Mesmo havendo maior produtividade de grãos no sistema de cultivo Milho Híbrido Solteiro-MHS, comparado com o Milho Brachiaria Linha-MBL, este é ultimo é mais recomendado para cultivo.

\section{REFERÊNCIAS}

ALVARENGA, R. C. et al. A Cultura do Milho na integração Lavoura-Pecuária. In:
CRUZ, J. C. et al. (Ed.). A Cultura do Milho. Sete Lagoas: Embrapa Milho e Sorgo, p.491-517, 2008.

ALVARENGA, R. C. et al. Rendimento do consórcio milho-brachiária brizantha afetado pela localização do adubo e aplicação de herbicida. Revista Brasileira de Milho e Sorgo (Impresso), v.10, p.224-234, 2011.

COBUCCI, T. Manejo integrado de plantas daninhas em sistema de plantio direto. In: ZAMBOLIN, L. (Ed.). Manejo integrado fitossanidade: cultivo protegido, pivô central e plantio direto. Viçosa, MG: UFV, 2001. p.583-624.

COLLIER, L. S. et al. Adubação fosfatada no sulco e em faixas sob palhada de leguminosa e produtividade de milho em plantio direto no Tocantins. Revista Ceres, v.55, p.109-116, 2008.

SAGRI-PA. Evolução das áreas, produção e rendimento do milho no estado do Pará - 2003 a 2009. Belém, 2009. Disponível em: <http://www.sagri.pa.gov.br/?q=node/125> . Acesso em: 15 mar. 2011.

SANTOS, J. S. et al. Um estudo da precipitação pluviométrica no município de Castanhal-Pa. In: CONGRESSO BRASILEIRO DE METEOROLOGIA, 14., 2006, Florianópolis. Anais... Florianópolis: SBMET, 2006. 
SILVA, F. de A. S.; AZEVEDO, C. A. V. de. Principal Components Analysis in the Software Assistat-Statistical Attendance. In: WORLD CONGRESS ON COMPUTERS IN AGRICULTURE, 7., 2009. Reno-NV-USA: American Society of Agricultural and Biological Engineers, 2009. 